\title{
DOES CREATINE SUPPLEMENTATION ENHANCE THE EFFECTS OF PHYSICAL TRAINING DURING PULMONARY REHABILITATION IN COPD?
}

Sarah J. Deacon, MRCP*, Emma E. Vincent, BSc*, Sally J. Singh, PhD*, Michael C. Steiner, MD, MRCP*, Paul Greenhaff, PhD\# and Michael D. Morgan, FRCP*

*Dept of Respiratory and Thoracic Medicine, Institute for Lung Health, Glenfield Hospital, Leicester, UK

\#Centre for Integrated Systems Biology and Medicine, University of Nottingham Medical School, Nottingham, UK

WINNING ABSTRACT: We conducted a randomised, placebo-controlled trial to examine whether creatine supplementation augments the benefits of pulmonary rehabilitation (PR), containing aerobic exercise and resistance training (RT).

80 subjects with COPD (GOLD stages I-IV) [mean (SD) age 68 (7.8) yrs, FEV 44.1 (20.3) \% predicted] completed 21 sessions of PR, with enhanced RT, following baseline measurements and randomisation to take creatine $(\mathrm{Cr})$ or placebo (PI) supplement. A subgroup had muscle biopsies.

Groups were well matched at baseline except for gender (M:F Cr 19:19, $\left.\mathrm{PI} \mathrm{31:11,} \mathrm{Chi}^{2} \mathrm{p}=0.03\right)$. Mean change in functional performance \& muscle strength after PR are shown. Health status (CRQ-SR) improved significantly after PR but did not differ between groups. Muscle biopsies showed evidence of creatine uptake.

This adequately powered study showed significant improvements in all outcomes following PR. Creatine supplementation did not enhance these benefits.

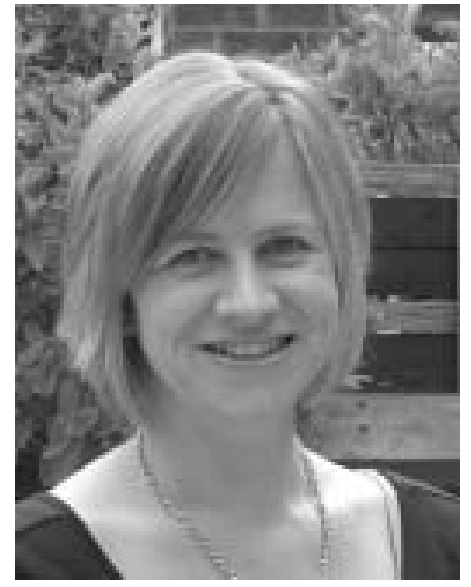

Sarah J. Deacon

Institute for Lung Health, Dept of Respiratory Medicine, University Hospitals of Leicester NHS Trust, Glenfield Hospital, Leicester, UK

\section{THE BACKGROUND TO OUR RESEARCH}

Chronic obstructive pulmonary disease (COPD) is the most common cause of disability due to lung disease. Patients are disabled by their inability to carry out many activities of daily living because of reduced exercise tolerance. This leads to social isolation, depression, and dependence and an increased burden on carers. General population ageing means that chronic disability due to COPD is expected to increase worldwide in the next three decades [1]. Improving physical performance in elderly patients is therefore an important therapeutic goal.

Exercise limitation does not correlate well with airway function and many patients will complain of leg fatigue, as well as breathlessness, as a prominent symptom that limits exercise [2-4]. Loss of muscle strength accompanies ageing and peripheral skeletal muscle dysfunction may be one of the primary determinants of disability in chronic lung disease [5]. Skeletal muscle strength and bulk are often reduced and there is evidence to suggest an impairment of oxidative metabolism [6]. Given that deconditioning is one of the principal causes of muscle dysfunction, exercise training is a logical step to improve physical performance. The role of exercise training in pulmonary rehabilitation is well established and is known to improve exercise capacity and health status in patients with chronic lung disease $[7,8]$. These improvements are partly due to metabolic adaptations in the peripheral muscles. Other benefits include a reduction in usage of health services and a decrease in the number of days spent in hospital following an acute admission [9]. The cost-effectiveness of introducing pulmonary rehabilitation to standard therapy has been demonstrated [10].

Nutritional supplements have been widely used in an attempt to increase muscle mass and enhance performance. More recently, there has been growing interest in creatine supplementation in various patient groups. Creatine is a naturally occurring substance and supplementation is popular amongst athletes to augment their training and performance [11]. It is thought that creatine, in its phosphorylated form, enhances performance by increasing the phosphagen pool available for rapid resynthesis of adenosine triphosphate from adenosine diphosphate during periods of high ATP turnover. It may also have a stimulatory effect on phosphocreatine (PCr) resynthesis [12]. Creatine can increase muscle bulk and enhance high intensity exercise training in healthy subjects. Uptake is increased by exercise and supplementaion is likely to be most beneficial when combined with training. There is evidence from muscle biopsy studies that $\mathrm{PCr}$ levels are lower in patients with COPD than in healthy subjects [13]. This may represent a potential therapeutic target to improve exercise performance. 




PR: pulmonary rehabilitation; Cl: confidence interval; FFM, fat-free mass; ISWT: incremental shuttle walking test; ESWT: endurance shuttle walking test. *: p<0.05; ** $p<0.01$.

Our hypothesis was that creatine supplementation in association with exercise training would augment the benefits of pulmonary rehabilitation. A number of studies have previously investigated the effects of creatine supplementation and there are possible benefits in neuromuscular disease, heart failure, cystic fibrosis and the healthy elderly. Recent metaanalyses suggest that creatine does enhance performance during resistance training programmes [14, 15]. Only one study on the effects of creatine supplementation in patients with COPD during pulmonary rehabilitation has been published, concluding that creatine increases fat-free mass, peripheral muscle strength and endurance and health status, but not exercise capacity [16]. This study [16] involved only a small sample of patients and a larger, randomised controlled trial is needed in order to apply the results to the general COPD population.

\section{MY JOB AND THE UNIT IN WHICH I WORK}

The Dept of Respiratory Medicine at Glenfield Hospital is part of the University Hospitals of Leicester NHS Trust, Leicester, UK. Our rehabilitation programme is one of the largest and was also one of the first to be established in the UK. Pulmonary rehabilitation is well established for patients with COPD, but we also include patients with other disabling respiratory illnesses.

I work within a large multidisciplinary team led by Dr Mike Morgan and Prof. Sally Singh. There is a strong background of research in our department involving physiotherapists, occupational therapists, nurses and doctors. The incremental and endurance shuttle walk tests and a self-administered form of the Chronic Respiratory Disease Questionnaire were developed through projects at Glenfield Hospital [17-19]. We are able to recruit large numbers of subjects into clinical trials due to the size of our rehabilitation programme. We have now developed a strong collaboration with Prof. Paul Greenhaff in Nottingham, UK, who is involved in our current research programme on muscle metabolism in COPD. With his help we have developed a safe technique to obtain peripheral muscle samples at rest and immediately after exercise in COPD patients. Using this technique we have shown that resting $\mathrm{PCr}$ levels in muscle correlates with the incremental shuttle walking distance, suggesting a role for $\mathrm{PCr}$ in determining maximal walking performance [20]. We have also shown that exercise induces a significant decline in ATP concentrations in muscle that is abolished after exercise training [21].

\section{MY WINNING POSTER AS PART OF MY RESEARCH}

I have recently completed an MD project entitled "Enhancement of cellular adaptation to physical training in chronic obstructive pulmonary disease. A randomised placebo controlled trial of creatine supplementation". This study was supported by a British Lung Foundation Project Grant. Patients attended a standard 7-week multidisciplinary pulmonary rehabilitation programme, consisting of three 2 -h sessions per week and comprising educational talks and strength and endurance training. The programme was enhanced with individually prescribed, progressive strength training exercises, closely monitored by a research nurse. Patients were randomised to receive creatine or placebo supplements administered during the course of pulmonary rehabilitation.

\section{THE IMPACT OF MY WORK ON CLINICAL OR RESEARCH PRACTICE}

Randomised controlled clinical trials such as this are difficult because large numbers of subjects are required and they need to be adequately powered to detect clinically important differences. Our preliminary results, presented in our winning abstract, suggest that creatine is not helpful in enhancing functional performance in subjects with COPD. Of course, there may be other ergogenic aids available that need to be studied.

\section{REFERENCES}

1 Murray CJ, Lopez AD. Alternative projections of mortality and disability by cause 1990-2020: Gobal Burden of Disease Study. Lancet 1997; 349: 1498-1504.

2 Levy RD, Ernst S, Levine SM, et al. Exercise performance after lung transplantation. J Heart Lung Transplant 1993; 12: 2-33.

3 Killian KJ, Leblanc P, Martin DH, Summers E, Jones NL, Campbell EJ. Exercise capacity and ventilatory, circulatory and symptom limitation in patients with chronic airflow limitation. Am Rev Respir Dis 1992; 146: 935-940. 
4 Killian KJ, Summers E, Jones NL, Campbell EJ. Dyspnea and leg effort during incremental cycle ergometry. Am Rev Respir Dis 1992; 145: 1339-1345.

5 Skeletal muscle dysfunction in chronic obstructive pulmonary disease. A statement of the American Thoracic Society and European Respiratory Society. Am J Respir Crit Care Med 1999; 159: S1-S40.

6 Gosselink R, Decramer M. Peripheral skeletal muscle and exercise performance in patients with chronic obstructive pulmonary disease. Monaldi Arch Chest Dis 1998; 53: 419-423.

7 Lacasse Y, Wong E, Guyatt GH, King D, Cook DJ, Goldstein RS. Meta-analysis of respiratory rehabilitation in chronic obstructive pulmonary disease. Lancet 1996; 348: 1115-1119.

8 Clark CJ, Cochrane L, Mackay E. Low intensity peripheral muscle conditioning improves exercise tolerance and breathlessness in COPD. Eur Respir J 1996; 9: 2590-2596.

9 Griffiths TL, Burr ML, Campbell IA, et al. Results at 1 year of outpatient multidisciplinary pulmonary rehabilitation; a randomised controlled trial. Lancet 2000; 355: 362-368.

10 Griffiths TL, Phillips CJ, Davies S, Burr ML, Campbell IA. Cost effectiveness of an outpatient multidisciplinary team pulmonary rehabilitation programme. Thorax 2001; 56: 779-784.

11 Greenhaff PL. Creatine and its application as an ergogenic aid. Int J Sport Nutr 1995; 5: Suppl., S100-S110.

12 Casey A, Constantin-Teodosiu D, Howell S, Hultman E, Greenhaff PL. Creatine ingestion favourably affects performance and muscle metabolism during maximal exercise in humans. Am J Physiol 1996; 271: E31-E37.
13 Fiaccadori E, Del Canale S, Vitali P, Coffrini E, Ronda N, Guariglia A. Skeletal muscle energetics, acid-base equilibrium and lactate metabolism in patients with severe hypercapnia and hypoxemia. Chest 1987; 92: 883-887.

14 Branch JD. Effect of creatine supplementation on body composition and performance: a meta-analysis. Int J Sport Nutr Exerc Metab 2003; 13: 198-226.

15 Nissen SL, Sharp RL. Effect of dietary supplements on lean mass and strength gains with resistance exercise: a metaanalysis. J Appl Physiol 2003; 94: 651-659.

16 Fuld JP, Kilduff LP, Neder JA, et al. Creatine supplementation during pulmonary rehabilitation in chronic obstructive pulmonary disease. Thorax 2005; 60: 531-537.

17 Singh SJ, Morgan MD, Scott S, Walters D, Hardman AE. Development of a shuttle walking test of disability in patients with chronic airways obstruction. Thorax 1992; 47: 1019-1024.

18 Revill SM, Morgan MD, Singh SJ, Williams J, Hardman AE. The endurance shuttle walk: a new field test for the assessment of endurance capacity in chronic obstructive pulmonary disease. Thorax 1999; 54: 213-222.

19 Williams JE, Singh SJ, Sewell L, Guyatt GH, Morgan MD. Development of a self-reported Chronic Respiratory Questionnaire (CRQ-SR). Thorax 2001; 56: 954-959.

20 Steiner MC, Sewell L, Patel P, et al. A technique for sampling the quadriceps muscle during exercise in patients with COPD. Thorax 2000; 55: Suppl. 3, A50.

21 Steiner MC, Sewell L, Patel P, et al. Endurance training improves skeletal muscle ATP turnover during exercise in COPD patients. Am J Respir Crit Care Med 2001; 163: Suppl. 5, A14. 